\title{
Generalized Quadratic Revenue Functions
}

\author{
ROBERT G. CHAMBERS \\ ROLF FÄRE \\ SHAWNA GROSSKOPF \\ MICHAEL VARDANYAN
}

\author{
CESIFO WORKING PAPER NO. 2404 \\ CATEGORY 10: EMPIRICAL AND THEORETICAL METHODS \\ SEPTEMBER 2008
}
An electronic version of the paper may be downloaded
- from the SSRN website: WwW.SSRN.com
- from the RePEc website: $\quad$ www.RePEc.org
- from the CESifo website: www.CESifo-group.org/wp




\title{
Generalized Quadratic Revenue Functions
}

\begin{abstract}
In this paper we focus on specification of revenue functions in their dual price space. We consider two distance functions, both dual to the revenue function: Shephard output distance function and the directional output distance function, both in price space. The former is multiplicative, satisfying homogeneity, the latter is additive satisfying transitivity. Functional equation methods yield translog specification for the Shephard case and quadratic for the directional case. Monte Carlo evidence suggests that the quadratic specification more precisely represents technology.
\end{abstract}

JEL Code: D24, C63.

Robert G. Chambers

Department of Agricultural and Resource

Economics

University of Maryland

College Park, MD

USA

rchambers@arec.umd.edu

Shawna Grosskopf Department of Economics

Oregon State University

Corvallis, OR 97331

USA

Shawna.Grosskopf@orst.edu
Rolf Färe

Department of Economics

Oregon State University

Corvallis, OR 97331

USA

Rolf.Fare@orst.edu

Michael Vardanyan

Luxembourg School of Finance

University of Luxembourg

Luxembourg

Vardanyan@bcl.lu

This version: August 2008 


\section{Introduction}

With the introduction of the Shortage Function (Luenberger, 1992, 1995) or Directional Distance Functions (Chambers, Chung and Färe, 1996) into economics, we have a new tool at our disposal for characterizing technology (or consumer preferences). These distance functions satisfy translation, a property that follows from their definition, and which corresponds to the more familiar homogeneity conditions that are characteristic of Shephard's distance functions. Both types of functions accommodate multiple inputs and outputs, which has proven useful in the performance measurement literature.

Another appealing feature of the distance functions is the fact that they have well-known economic dual representations. For example, the revenue function is a Shephard (1970) type output distance function in price space. Here we derive the companion directional output distance function in price space, which is also dual to Shephard's output distance function. We then propose to compare these two price space distance functions in terms of their ability to represent technology in price space. Our approach is to parameterize these distance functions within the family of generalized quadratic functions and undertake a Monte Carlo experiment to assess their relative ability to describe the price space technology. Since both distance functions fully characterize the price space technology, we have two alternatives for its representation. The Monte Carlo experiment will provide guidance as to which distance function performs better empirically.

In a recent paper Färe, Martins-Filho and Vardanyan (2008) use a similar research design to compare the econometric performance of Shephard and Directional Distance Functions in output quantity space in a production context. Based on their Monte Carlo experiment they conclude that the directional distance function does a better job of modeling the technology within the family of generalized quadratic functions in quantity space. Färe et al. (in press) study these functions in the consumer theory context and come to a similar conclusion.

We exploit the translation and homogeneity properties to help us choose appropriate functional forms for parameterizing our distance functions. We employ functional equation techniques to identify the functional forms that satisfy the aforementioned properties as well as flexibility and linearity in parameters, i.e., they satisfy properties from economic theory as well as providing practical empirical properties. In contrast, in a recent study Feng and Serletis (2008) state that '...there is no a priori view as to which flexible functional forms are appropriate...' Our goal is to suggest a fruitful alternative to this view. 


\section{Parametric Generalized Quadratic Functions}

In this section we introduce the generalized quadratic function - a flexible functional form - and show how it may be parameterized using homogeneity and translation properties, i.e., the generalized quadratic function belongs to a class of functions that nest translation and homogeneity properties. Recall that the revenue function is homogeneous in output prices and that it is an output distance function in price space. The 'new' revenue function introduced in this paper as a directional output distance function in price space is shown below to satisfy the translation property. Homogeneity and translation are the properties we use to help us parameterize these functions.

Let

$$
F: \Re{ }^{I} \rightarrow \Re, h: \Re \rightarrow \Re
$$

and $\zeta: \Re \rightarrow \Re$ with inverse $\zeta^{-1}$ and let $a_{i}, a_{i j}$ be real constants and $q_{i} \in \Re$, then

$$
\zeta^{-1}(F(q))=a_{o}+\sum_{i=1}^{I} a_{i} h\left(q_{i}\right)+\sum_{i=1}^{I} \sum_{j=1}^{I} a_{i j} h\left(q_{i}\right) h\left(q_{j}\right)
$$

is called a generalized quadratic function (Chambers, 1988), a transformed quadratic function (Diewert, 2002 ) or is said to have a second-order Taylor's series approximation interpretation (Färe and Sung, 1986). If $a_{i}=0, i=1, \ldots, I$ and $a_{i j} \neq 0, i=1, \ldots, I$, then it is a generalized quasi-quadratic function (Färe and Sung, 1986).

We say that $F(q)$ is homogeneous of degree +1 if

$$
F(\lambda q)=\lambda F(q), \lambda>0
$$

and it satisfies the translation property if

$$
F(q+\alpha g)=F(q)+\alpha, \alpha \in \Re
$$

where $g=\left(g_{1}, \ldots, g_{I}\right) \in \Re^{I}, g \neq 0$ is the directional vector. ${ }^{1}$

Note that the generalized quadratic function (1) is linear in the parameters $a_{i}$ and $a_{i j}$ and that it is quadratic in $h($.$) . The first property is desirable from an econometric point of view and the second$

\footnotetext{
${ }^{1}$ In efficiency analysis this is the direction in which efficiency and productivity are measured (Chambers, Chung and
} Färe, 1996). 
from an economic point of view.

The interaction between (1) and (2) or between (1) and (3) yield functional equations. What we seek are the solutions to these functional equations, which will provide the 'functional form' that globally satisfies the conditions (1) and (2) or (2) and (3). As it turns out, there are two solutions for each pair of conditions, which provide the basis for our choice of parameterization. Beginning with (1) and (2), i.e., our generalized form in combination with homogeneity, yields the following solutions (see Färe and Sung, 1986):

$$
F(q)=a_{o}+\sum_{i=1}^{I} a_{i} \ln \left(q_{i}\right)+\sum_{i=1}^{I} \sum_{j=1}^{I} a_{i j} \ln \left(q_{i}\right) \ln \left(q_{j}\right),
$$

namely the translog function (Christensen, et al, 1971), and

$$
F(q)=\left(a_{o}+\sum_{i=1}^{I} \sum_{j=1}^{I} a_{i j} q_{i}^{r / 2} q_{j}^{r / 2}\right)^{1 / r}
$$

which is the quadratic mean of order $r$ function.

The functional equations (1) and (3), i.e., generalized quadratic and translation, with $g=(1, \ldots, 1)$ yield two solutions as well (Färe and Lundberg, 2006)

$$
F(q)=a_{o}+\sum_{i=1}^{I} a_{i}\left(q_{i}\right)+\sum_{i=1}^{I} \sum_{j=1}^{I} a_{i j}\left(q_{i}\right)\left(q_{j}\right),
$$

the quadratic function, and

$$
F(q)=\frac{1}{2 \lambda} \ln \sum_{i=1}^{I} \sum_{j=1}^{I} a_{i j} \exp \left(\lambda q_{i}\right) \exp \left(\lambda q_{j}\right), \lambda \neq 0
$$

an unnamed function. ${ }^{2}$

In passing, we mention that Diewert (1971) and Diewert and Wales (1987) introduced the generalized Leontief and the normalized quadratic functions. These have the forms

$$
F(q)=\sum_{i=1}^{I} a_{i} q_{i}+\sum_{i=1}^{I} \sum_{j=1}^{I} a_{i j} q_{i}^{1 / 2} q_{j}^{1 / 2}
$$

and

\footnotetext{
${ }^{2}$ Chambers (1998) suggested (6) and (7) (with $\lambda=1 / 2$ ) as possible parameterizations of the directional distance function.
} 


$$
F(q)=\sum_{i=1}^{I} a_{i} q_{i}+\frac{\sum_{i=1}^{I} \sum_{j=1}^{I} a_{i j} q_{i} q_{j}}{\sum_{i=1}^{I} b_{i} q_{i}}
$$

respectively. These two homogeneous function belong to a more general class than the generalized quadratic, namely, they are of the form

$$
\zeta^{-1}(F(q))=a_{o}+\sum_{i=1}^{I} a_{i} h\left(q_{i}\right)+\sum_{i=1}^{I} \sum_{j=1}^{I} a_{i j} f\left(q_{i}\right) f\left(q_{j}\right)
$$

and

$$
\zeta^{-1}(F(q))=a_{o}+\sum_{i=1}^{I} a_{i} h\left(q_{i}\right)+\frac{\sum_{i=1}^{I} \sum_{j=1}^{I} a_{i j} f\left(q_{i}\right) f\left(q_{j}\right)}{g(q)} .
$$

Note that these differ from the generalized quadratic family of functional forms in (1) in that they include additional functions $f\left(q_{i}\right) f\left(q_{j}\right)$ in (10) as well as $g(q)$ in (11). Not much is known about the functional equations generated by (10), (2), (3) and (11), (2), (3).

\section{Generalized Quadratic Revenue Functions}

Let $x \in \Re_{+}^{N}$ denote inputs and $y \in \Re_{+}^{M}$ outputs; we model technology here by its output sets

$$
P(x)=\{y: x \text { can produce } y\}, x \in \Re_{+}^{N} .
$$

We assume that the output sets satisfy the usual axioms including free disposability of inputs and outputs, $P(x)$ nonempty and compact for $x \in \Re_{+}^{N}$, see Färe and Primont (1995) for details.

Let $p \in \Re_{+}^{M}$ be an output price vector, with the corresponding revenue function defined as

$$
R(x, p)=\max \{p y: y \in P(x)\}, x \in \Re_{+}^{N} .
$$

This function is homogeneous of degree +1 in output prices

$$
R(x, \lambda p)=\lambda R(x, p), \lambda>0 .
$$

Let $R$ be a given revenue value, then the associated output set in price space is

$$
P(x, R)=\{p: R(x, p) \leqq R\}
$$

These price output sets have the following properties (see Shephard, 1970): 
i. closed

ii. convex

iii. monotonic.

We note that the revenue function is an output distance function in price space, i.e.,

$$
\begin{aligned}
D(x, p, R) & =\inf \{\lambda:(p / \lambda) \in P(x, R)\} \\
& =\inf \{\lambda: R(x, p / \lambda) \leqq R)\} \\
& \left.=\inf \left\{\lambda: \frac{R(x, p)}{R} \leqq \lambda\right)\right\} \\
& =\frac{R(x, p)}{R} .
\end{aligned}
$$

The second equality follows from the definition of the output set in price space and the third from the homogeneity of the revenue function in output prices. Next, let $g=\left(g_{1}, \ldots, g_{M}\right) \neq 0$ be a directional vector, then the directional revenue function is defined as

$$
\begin{aligned}
\triangle(x, p, R ; g) & =\sup \{\beta:(p+\beta g) \in P(x, R)\} \\
& =\sup \{\beta: R(x, p+\beta g) \leqq R\} .
\end{aligned}
$$

Note that if $p=g$, then

$$
\begin{aligned}
\triangle(x, p, R ; g) & =\sup \{\beta: R(x, p(1+\beta)) \leqq R\} \\
& =-1+\sup \{(1+\beta): R(x, p)(1+\beta) \leqq R\} \\
& =\frac{R}{R(x, p)}-1 \\
& =\frac{1}{D(x, p, R)}-1
\end{aligned}
$$

which shows the relationship between the directional revenue function and the revenue function $R(x, p)$, or equivalently the price output distance function $D(x, p, R)$.

We illustrate the price output distance function and directional revenue function in the following figure. Both panels are of the same output price technology, $P(x, p, R)$ and evaluate the observed output 


\section{Shephard dist fn, $D((x, p, R)$}

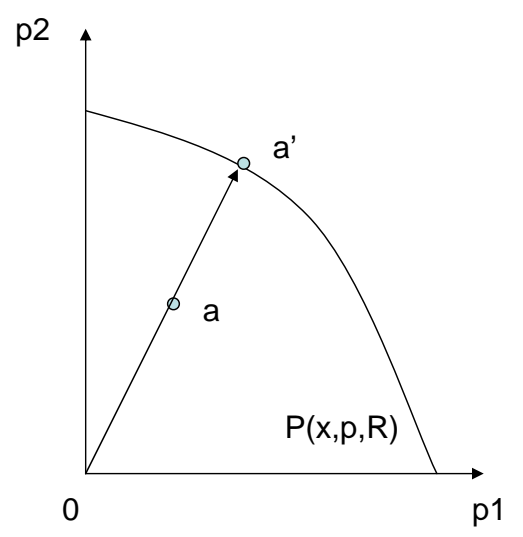

\section{Directional revenue function}

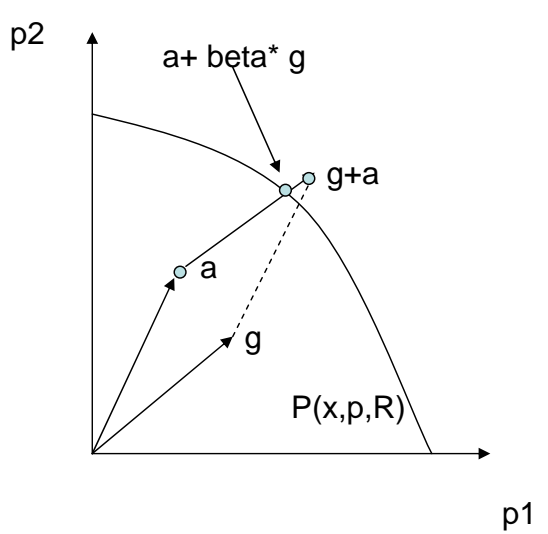

price pair at $a$. The Shephard price output distance function projects $a$ to the frontier of technology along a ray from the origin, i.e., for observation $a D(x, p, R)=0 a^{\prime} / 0 a$. The directional revenue function for observation $a$ is in the right hand panel; here the problem is maximize $\left(p_{1}, p_{2}\right)+\beta g$ with respect to $\beta . g$ is the direction vector which we add to $a$. We then scale along the segment $a, g+a$ until we reach the frontier at $\left(p_{1}, p_{2}\right)+\triangle(x, p, R ; g) g$. if the direction vector had been $g=\left(p_{1}, p_{2}\right)$, then the direction vector would lie on the ray from the origin, and the resulting value would be equal to $\frac{1}{D(x, p, R)}-1$.

From its definition, it follows that $\triangle(x, p, R ; g)$ satisfies the translation property, i.e., ${ }^{3}$

$$
\triangle(x, p+\alpha g, R ; g)=\triangle(x, p, R ; g)+\alpha .
$$

The following lemma establishes the relationship between the two revenue functions $\triangle(x, p, R ; g)$ and $R(x, p)$. The proof is in the appendix.

LEMMA: $\triangle(x, p, R ; g)=0 \Leftrightarrow R(x, p)=R$.

Thus the two revenue functions model the same price space technology $P(x, R)$. Using this lemma we may write the directional revenue function as

\footnotetext{
${ }^{3}$ For the case in which $g=(1, \ldots, 1)(19)$ corresponds to $(3)$.
} 


$$
\triangle(x, p, R(x, p) ; g)
$$

If the revenue function is differentiable, we may derive the following marginal conditions from (20)

$$
\partial R / \partial p_{m}=-\frac{\partial \triangle / \partial p_{m}}{\partial \triangle / \partial R}, m=1, \ldots, M
$$

and

$$
\partial R / \partial x_{n}=-\frac{\partial \triangle / \partial x_{n}}{\partial \triangle / \partial R}, n=1, \ldots, N
$$

where (21) yields the supply functions for outputs and (22) gives us the shadow prices of the inputs. Note that the left hand side is based on the usual revenue function whereas the right hand side is the directional revenue function. Thus one may estimate $\triangle(x, p, R ; g)$ and derive the desirable properties of $R(x, p)$.

To illustrate this derivation we provide a simple example of (20). Let technology be a simple production function

$$
F(x)=\max \{y: y \in P(x)\}, y \in \Re_{+}^{M}
$$

with

$$
y=\sqrt{x} .
$$

The corresponding revenue function is

$$
R(x, p)=p \sqrt{x} .
$$

The directional revenue function with $g=1$ is

$$
\begin{aligned}
\triangle(x, p, R ; 1) & =\max \{\beta:(p+\beta) \sqrt{x} \leqq R\} \\
& =\max \{\beta: p \sqrt{x}+\beta \sqrt{x} \leqq R\} \\
& =\max \left\{\beta: \beta \leqq \frac{R}{\sqrt{x}}-p\right\} \\
& =\frac{R}{\sqrt{x}}-p .
\end{aligned}
$$

The supply function associated with (25) equals 


$$
\partial R / \partial p=\sqrt{x}
$$

From (26) we have

$$
\partial \triangle / \partial p=-1
$$

and

$$
\partial \triangle / \partial R=\frac{1}{\sqrt{x}}
$$

thus

$$
\frac{\partial \triangle / \partial p}{\partial \triangle / \partial R}=\sqrt{x}=\partial R / \partial p .
$$

In our Monte Carlo experiment, we parameterize the usual revenue function as a translog function given the homogeneity of the revenue function. We parameterize the directional revenue function as a quadratic, consistent with the translation property of the directional revenue function. We choose translog and quadratic over the other possible solutions because they have both first and second order terms.

\section{The Monte Carlo Experiments}

Throughout this section we follow the setup of the experiment outlined in Färe, Martins-Filho, and Vardanyan (2008) and our Monte Carlo experiments focus on two classes of the true price space technologies. We assume three so-called polynomial-of-order-four technologies (P1, P3, P3) which give us our 'translation' quadratic technology and three translog-of-order-four technologies (L1, L2, L3) which satisfy homogeneity. Since we are mainly interested in the shape of the frontier of the price output set, we assume that only one input is used to generate two output prices. The values of this input are set to unity for all simulated observations in our samples. This normalization will aid in the visual assessment of the quality of approximation, as the price output set is specified for a given level of input utilization. Moreover, we apply the same normalization to the revenue.

Beginning with the polynomial-of-order-four technologies (P), we have

$$
P^{Q}(1,1)=\left\{\left(p_{1}, p_{2}\right): p_{2}=f^{Q}\left(p_{1}\right)\right\}
$$


where $f^{Q}\left(p_{1}\right)=\left(\beta_{0}^{Q}+\beta_{1}^{Q} p_{1}+\beta_{2}^{Q} p_{1}^{2}+\beta_{3}^{Q} p_{1}^{3}+\beta_{4}^{Q} p_{1}^{4}\right)$ definesthefrontierofthepriceoutputset ${ }^{4}$, and the parameter vector $\beta^{Q}=\left(\beta_{0}^{Q}, \ldots, \beta_{4}^{Q}\right)$ models the degree of its concavity. The three assumed scenarios cover a wide range of possibilities and at the same time allow for relatively simple interpretation of the simulation results. The parameters are chosen in the following way:

\begin{tabular}{cccc}
\hline \multicolumn{4}{c}{ Quadratic Functional Form } \\
\hline & Model P1 & Model P2 & Model P3 \\
\hline$\beta_{0}^{Q}$ & 11.70 & 11.10 & 10.60 \\
$\beta_{1}^{Q}$ & -0.91 & -0.72 & -0.54 \\
$\beta_{2}^{Q}$ & $0.50 \times 10-5$ & $0.50 \times 10-4$ & $0.10 \times 10-2$ \\
$\beta_{3}^{Q}$ & $0.10 \times 10-4$ & $0.10 \times 10-3$ & $0.10 \times 10-2$ \\
$\beta_{3}^{Q}$ & $-0.45 \times 10-3$ & $-0.12 \times 10-2$ & $-0.24 \times 10-2$ \\
\hline
\end{tabular}

Note that this setup can be extended to a more general case involving more than one production input. However, given the goals of the experiment, such a generalization is not necessary, since the above setup already includes the possibility of multiple inputs through our choice of the parameter vector $\beta^{Q} .{ }^{5}$ Panel (A) of Figure 1 illustrates the plots of the price output set frontiers for the valid range of the first output price. Model P1 has the 'flattest' price output frontier, and Model P3 the most curvature.

The prices $p_{1}$ are generated by drawing samples of various sizes $(\mathrm{K})$ from a gamma distribution with the density given by $f\left(p_{1}\right)=p^{\lambda-1} e^{-p_{1} / \theta}\left(\Gamma(\lambda) \theta^{\lambda}\right)^{-1}$, where $\Gamma(\cdot)$ is the gamma function, with $(\lambda, \theta) \in \Re_{+}^{2}$. We assume the following three cases with regards to the true sample size: $K=50, K=100$, and $K=500$.

Our class of polynomial technologies is further divided into two subclasses, type- A and type-B models, which differ by the values of the parameter vector $(\lambda, \theta)$ that we assume for the experiment. Specifically, type-A specifications have $(\lambda, \theta)=(5,0.5)$, whereas type-B models assume $(\lambda, \theta)=(18,0.25){ }^{6}$ The prices $p_{2}$ for the polynomial (quadratic) technologies are then generated as $p_{2}=f^{Q}\left(p_{1}\right)-\nu$, where

\footnotetext{
${ }^{4}$ During the initial stages of our research we have experimented with a number of additional cases involving other shapes of the true price output set boundaries. The outcomes of these experiments are very similar to the results that we describe in the next section.

${ }^{5}$ We have also considered several cases in which the actual quantities of two production inputs were assumed and included in the experiment directly. However, this generalization did not change our results.

${ }^{6}$ The type-A parameters yield data with relatively low values of $p_{1}$ and relatively high values of $p_{2}$, whereas typeB parameters yield relatively 'more balanced' prices. This turned out not to matter in terms of the quality of the approximation. As a consequence we assume just one class of true technologies in the translog case, where we used a uniform distribution to draw the data for $p_{1}$.
} 
the random noise $\nu$ captures the price-space counterpart to 'technical inefficiency' and is assumed to have an exponential distribution with the density $f(\nu)=\exp -\nu$.

Turning next to the specification of the translog price technologies $(\mathrm{L})$, we have

$$
P^{L}(1,1)=\left\{\left(p_{1}, p_{2}\right): \ln \left(p_{2}\right)=f^{L}\left(p_{1}\right)\right\}
$$

where $f^{L}\left(p_{1}\right)=\beta_{0}^{L}+\beta_{1}^{L}\left(\ln p_{1}\right)+\beta_{2}^{L}\left(\ln p_{1}^{2}\right)+\beta_{3}^{L}\left(\ln p_{1}^{3}\right)+\beta_{4}^{L}\left(\ln p_{1}^{4}\right)$ and the parameter vector $\beta^{L}=$ $\left(\beta_{0}^{L}, \ldots, \beta_{4}^{L}\right)$ is chosen in the following way: ${ }^{7}$

\begin{tabular}{cccc}
\hline \multicolumn{4}{c}{ Translog Functional Form } \\
\hline & Model L1 & Model L2 & Model L3 \\
\hline$\beta_{0}^{L}$ & 3.000 & 2.845 & 2.690 \\
$\beta_{1}^{L}$ & -3.500 & -3.400 & -3.300 \\
$\beta_{2}^{L}$ & 3.900 & 4.000 & 4.100 \\
$\beta_{3}^{L}$ & -1.500 & -1.475 & -1.415 \\
$\beta_{4}^{L}$ & -0.140 & -0.220 & -0.330 \\
\hline
\end{tabular}

Panel (B) of Figure 1 illustrates the plots of the corresponding boundaries for the translog case. We draw the samples of the same three sizes as before from the uniform distribution as $\ln \left(p_{1}\right) \sim$ Uniform $(0.7,1.4)$ to ensure that all of the true price output set frontiers have non-decreasing pricespace counterparts of the marginal rate of transformation at each value of $p_{1}$. As in the case of the polynomial technologies, the three choices allow us to keep the experiment both reasonably general as well as easily interpretable. Finally, the price-space counterpart of 'technical inefficiency' is introduced in a similar way as before, i.e., $\ln \left(p_{2}\right)=\ln \left(\exp \left\{f^{L}\left(p_{1}\right)\right\}-\nu\right)$.

The translog and the quadratic output distance functions in price space are given respectively by

$$
\ln D(1, p, 1)=\gamma_{0}+\gamma_{1} \ln p_{1}+\gamma_{2} \ln p_{2}+\frac{\gamma_{11}}{2}\left(\ln \left(p_{1}\right)\right)^{2}+\frac{\gamma_{22}}{2}\left(\ln \left(p_{2}\right)\right)^{2}+\gamma_{12} \ln p_{1} \ln p_{2}
$$

and

$$
\triangle(1, p, 1)=\delta_{0}+\delta_{1} p_{1}+\delta_{2} p_{2}+\frac{\delta_{11}}{2} p_{1}^{2}+\frac{\delta_{22}}{2} p_{2}^{2}+\delta_{12} p_{1} p_{2}
$$

respectively.

We use the linear programming techniques popularized by Aigner and Chu (1968) to compute the parameter estimates of these as frontier functions. Their properties, such as representation, monotonic-

\footnotetext{
${ }^{7}$ Both $\beta^{L}$ and $\beta^{Q}$ are assumed to be the same as in Färe, Martins-Filho and Vardanyan (2008).
} 
ity, translation and homogeneity, have been imposed and satisfied during each of the 200 replications. ${ }^{8}$ Finally, we consider three choices of the directional vector g, which enters problem (34) via translation property constraints: $\mathrm{g}=(10,1), \mathrm{g}=(1,1)$, and $\mathrm{g}=(1,10)$.

In the next stage of the experiment we use parameter estimates from (33) and (34) to obtain the estimated price-space frontiers and then visually assess the quality of approximation provided by the translog and the quadratic parameterizations. We start by assuming price-space technical efficiency for every observation in the sample, i.e., $\triangle^{k}(1, p, 1: g)=0$ and $D^{k}(1, p, 1)=1$ for all $k=1, \ldots, K$, and then substitute the quantities representing the first output price to solve $\mathrm{K}$ quadratic equations. The solutions to these equations, $p_{2 k}^{*}(\hat{\gamma})$ and $p_{2 k}^{*}(\hat{\delta})$, place every observation on the estimated boundary of the price output set producing its plot.

The following three benchmarks are used to assess the quality of our parametric approximations:

1. The average Euclidean distance between the true and simulated prices of the second output.

2. The average discrepancy between the price-space counterparts of the relative shadow prices.

3. The mean Euclidean distance between the true and estimated price-space measures of the frontier curvature. This measure can be interpreted as the price-space counterpart of the Morishima elasticity of substitution [Morishima (1967)].

The first benchmark is obtained using the true and estimated prices of the second output and is defined as

$$
\bar{\Theta}(\hat{\gamma})=K^{-1}\left(\sum_{k=1}^{K}\left[p_{2 k}^{*}(\hat{\gamma})-f^{L}\left(p_{1 k}\right)\right]^{2}\right)^{1 / 2}
$$

and

$$
\bar{\Theta}(\hat{\delta})=K^{-1}\left(\sum_{k=1}^{K}\left[p_{2 k}^{*}(\hat{\delta})-f^{Q}\left(p_{1 k}\right)\right]^{2}\right)^{1 / 2}
$$

in the translog and polynomial models, respectively.

The second benchmark can be interpreted as the average discrepancy between the true and estimated price-space counterparts of the marginal rate of transformation evaluated at frontier points. From duality

\footnotetext{
${ }^{8}$ See Chambers, Chung and Färe (1998) and Färe and Grosskopf (1994) for an in-depth discussion of the distance function properties.
} 
theory, the relative shadow quantities can be defined as (Färe and Primont (1995); Färe and Grosskopf $(2004))$

$$
\psi=\frac{\partial D(1, p, 1) / \partial p_{1}}{\partial D(1, p, 1) / \partial p_{2}}=\frac{\partial \triangle(1, p, 1 ; g) / \partial p_{1}}{\partial \triangle(1, p, 1: g) / \partial p_{2}} .
$$

Hence, the average Euclidean distance between the true and estimated price-space representations of relative shadow quantities is equal to

$$
\bar{\Omega}(\hat{\gamma})=K^{-1}\left(\sum_{k=1}^{K}\left(\rho_{k}+\frac{\partial \ln D\left(1, p_{1 k}, p_{2 k}, 1\right) / \partial \ln \left(p_{1}\right)}{\partial \ln D\left(1, p_{1 k}, p_{2 k}, 1\right) / \partial \ln \left(p_{2}\right)} \frac{p_{2 k}}{p_{1 k}}\right)^{2}\right)^{1 / 2},
$$

and

$$
\bar{\Theta}(\hat{\gamma})=K^{-1}\left(\sum_{k=1}^{K}\left(\rho_{k}+\frac{\partial \triangle\left(1, p_{1 k}, p_{2 k}, 1\right) / \partial\left(p_{1}\right)}{\partial \triangle\left(1, p_{1 k}, p_{2 k}, 1\right) / \partial\left(p_{2}\right)}\right)^{2}\right)^{1 / 2},
$$

where $\rho_{k}$ is the negative of the true shadow quantities for observation k. Note that $\rho_{k}=\frac{\partial f^{Q}\left(p_{1 k}\right)}{\partial p_{1}}$ in the case of polynomial technologies and $\rho_{k}=\frac{\partial f^{L}\left(p_{1 k}\right)}{\partial \ln p_{1}} \frac{p_{2 k}}{p_{1 k}}$ for translog technologies.

Finally, our third benchmark assesses the relative error in the approximation of the price output set curvature. It is defined as $\partial \ln \psi / \partial \ln \left(p_{2} / p_{1}\right)$ and we have

$$
\begin{aligned}
e_{k}(\hat{\gamma}) & =1-\frac{\partial^{2} \ln D\left(1, p_{k}, 1\right)}{\partial\left(\ln p_{1}\right)^{2}} \partial \ln D\left(1, p_{k}, 1\right) / \partial \ln p_{1}+\frac{\partial^{2} \ln D\left(1, p_{k}, 1\right)}{\partial\left(\ln p_{1}\right) \partial\left(\ln p_{2}\right)} \partial \ln D\left(1, p_{k}, 1\right) / \partial \ln p_{2} \\
& =1-\frac{\hat{\gamma}_{11}}{\hat{\gamma}_{1}+\hat{\gamma}_{11} \ln p_{1 k}+\hat{\gamma}_{12} \ln p_{2 k}}+\frac{\hat{\gamma}_{12}}{\hat{\gamma}_{2}+\hat{\gamma}_{22} \ln p_{2 k}+\hat{\gamma}_{12} \ln p_{1 k}}
\end{aligned}
$$

and

$$
\begin{aligned}
e_{k}(\hat{\delta}) & =p_{1}\left(\frac{\partial^{2} \triangle\left(1, p_{k}, 1 ; g\right) / \partial p_{1} p_{2}}{\partial \triangle\left(1, p_{k}, 1 ; g\right) / \partial p_{2}}-\frac{\partial^{2} \triangle\left(1, p_{k}, 1 ; g\right) / \partial p_{1}^{2}}{\partial \triangle\left(1, p_{k}, 1 ; g\right) / \partial p_{1}}\right) \\
& =p_{1}\left(\frac{\hat{\delta}_{12}}{\hat{\delta}_{2}+\hat{\delta}_{22} p_{2 k}+\hat{\delta}_{12} p_{1 k}}-\frac{\hat{\delta}_{11}}{\hat{\delta}_{1}+\hat{\delta}_{11} p_{1 k}+\hat{\delta}_{12} p_{1 k}}\right)
\end{aligned}
$$

Therefore, the mean Euclidean distance is equal to

$$
\bar{E}(\cdot)=K^{-1} \sum_{k=1}^{K}\left(\left(e_{k}+e_{k}(\cdot)\right)^{2}\right)^{1 / 2}
$$


where $e_{k}$ is the negative of the true price-space elasticity of substitution for observation k. Also, note

that $e_{k}=\frac{\partial^{2} f^{L}\left(p_{1 k}\right) / \partial \ln p_{1}^{2}}{\partial f^{L}\left(p_{1 k}\right) / \partial \ln p_{1}}-1$ and $e_{k}=p_{1 k} \frac{\partial^{2} f^{Q}\left(p_{1 k}\right) / \partial p_{1}^{2}}{\partial f^{Q}\left(p_{1 k}\right) / \partial p_{1}}$ for translog and polynomial technologies, respectively.

\section{Results}

The quality of approximation of the price output set frontier attained by the quadratic directional revenue function is better than that achieved by the translog revenue function. This conclusion is based on the visual comparison of plots in Figure 2 and Figure 3, as well as via a more rigorous investigation of the simulation results summarized in Table 1.

The estimated frontiers that were recovered using the parameters of the translog revenue function all have the wrong curvature in both classes of the true technologies used in the experiment. For example, in Figure 2-which is based on data generated from a 'true' quadratic function - we would expect that estimation using the translog functional form would yield relatively poorer results than the quadratic, which it does - compare top and bottom panels in Figure 2. However, even when the 'true' technology is translog as in Figure 3, estimation using the translog functional form yields estimates of the frontier that again have the wrong curvature. This result is confirmed by the average estimated counterpart to the deviations between the estimated and true elasticity of substitution, which, regardless of the directional vector assumed, is always smaller in all of the quadratic specifications than the translog.

Note also that while an increase in the sample size always produces a closer approximation in the quadratic parameterizations (compare $\bar{\Theta}, \bar{\Omega}, \bar{E}$ for $\triangle(\cdot)$ (quadratic) versus $D(\cdot)$ in Table 1), similar increases in $\mathrm{K}$ generally result in poorer quality of approximation when the data is generated as translog for both $\triangle(\cdot)$ and $D(\cdot)$, although this is more pronounced with $D(\cdot)$ despite the fact that the data were generated as translog (see Table 2). 
Figure 1

True Frontiers of the Price Space Output Set

I. Polynomial Technologies

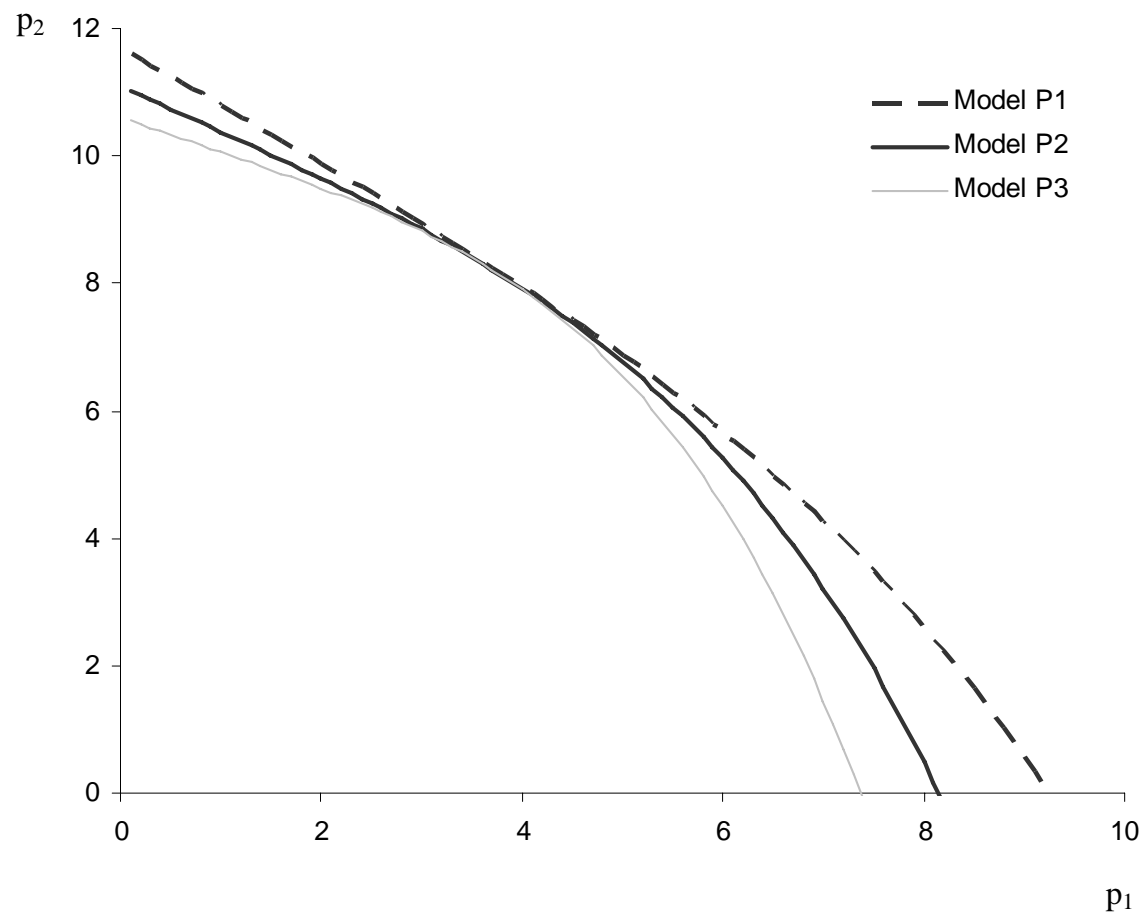

II. Translog Technologies

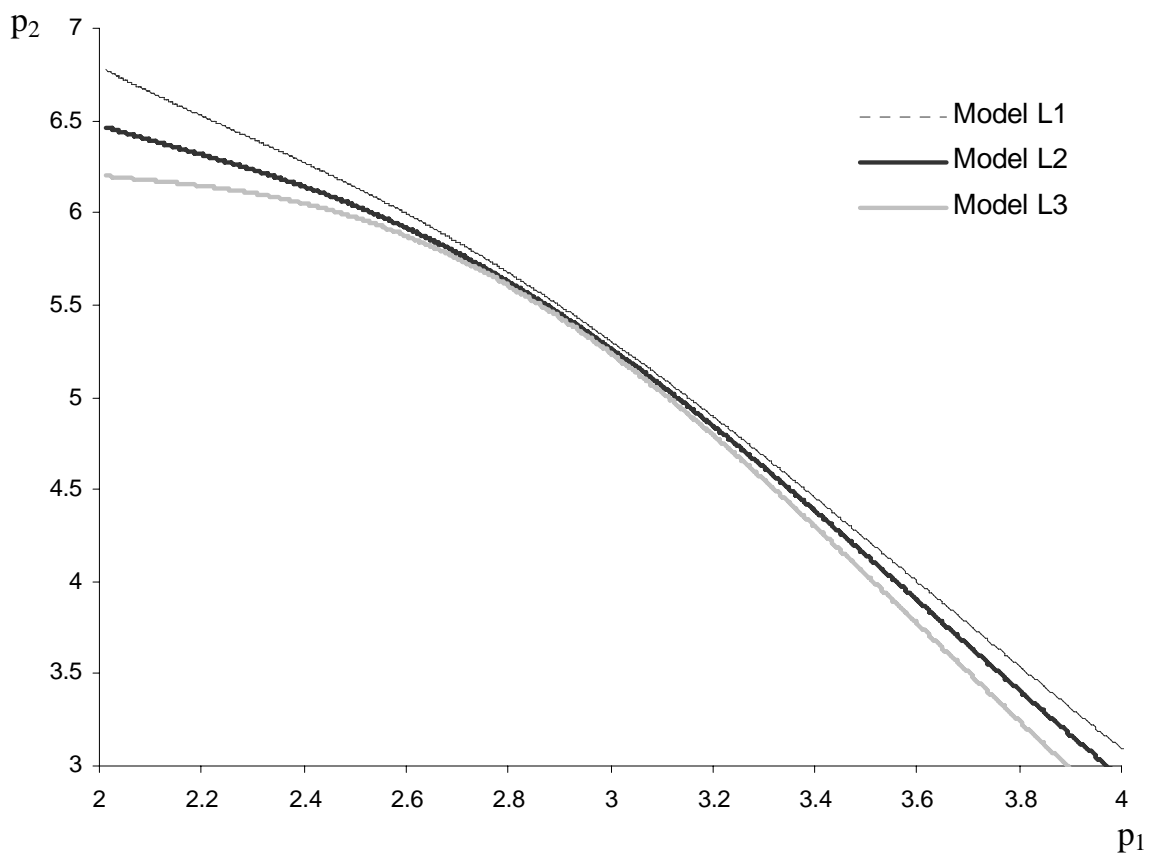


Table 1

Results of the Monte Carlo Experiment;

P1 Models*

\begin{tabular}{ccccc}
\hline \multicolumn{2}{l}{ Type-A Models } & $\bar{\Theta}(\cdot)$ & $\bar{\Omega}(\cdot)$ & $\overline{\mathrm{E}}(\cdot)$ \\
\hline$\Delta(1, p, 1 ; g)$ & $g=(1,10)$ & & & \\
& $\mathrm{K}=50$ & 0.065 & 0.072 & 0.188 \\
$\mathrm{~K}=100$ & 0.037 & 0.043 & 0.115 \\
$\mathrm{~K}=500$ & 0.012 & 0.019 & 0.078 \\
$g=(1,1)$ & & & \\
$\mathrm{K}=50$ & 0.065 & 0.072 & 0.104 \\
$\mathrm{~K}=100$ & 0.038 & 0.044 & 0.083 \\
$\mathrm{~K}=500$ & 0.013 & 0.020 & 0.080 \\
$g=(10,1)$ & & & \\
& $\mathrm{K}=50$ & 0.068 & 0.074 & 0.106 \\
& $\mathrm{~K}=100$ & 0.041 & 0.050 & 0.115 \\
$\mathrm{~K}=500$ & 0.015 & 0.021 & 0.119 \\
\hline$D(1, p, 1)$ & & & & \\
& $\mathrm{K}=50$ & 0.098 & 0.168 & 1.158 \\
& $\mathrm{~K}=100$ & 0.086 & 0.153 & 0.816 \\
$\mathrm{~K}=500$ & 0.124 & 0.190 & 0.584 \\
\hline \hline
\end{tabular}

Type-B Models

\begin{tabular}{lllll}
\hline$\Delta(1, p, 1 ; g)$ & $g=(1,10)$ & & & \\
& $\mathrm{K}=50$ & 0.065 & 0.078 & 0.344 \\
$\mathrm{~K}=100$ & 0.035 & 0.044 & 0.215 \\
$\mathrm{~K}=500$ & 0.014 & 0.025 & 0.169 \\
$g=(1,1)$ & & & \\
$\mathrm{K}=50$ & 0.065 & 0.074 & 0.219 \\
$\mathrm{~K}=100$ & 0.036 & 0.044 & 0.208 \\
& $\mathrm{~K}=500$ & 0.012 & 0.018 & 0.248 \\
& $g=(10,1)$ & & & \\
& $\mathrm{K}=50$ & 0.063 & 0.067 & 0.434 \\
& $\mathrm{~K}=100$ & 0.032 & 0.037 & 0.435 \\
& $\mathrm{~K}=500$ & 0.007 & 0.011 & 0.444 \\
\hline$D(1, p, 1)$ & & & & \\
& $\mathrm{K}=50$ & 0.080 & 0.101 & 0.479 \\
& $\mathrm{~K}=100$ & 0.063 & 0.098 & 0.459 \\
& $\mathrm{~K}=500$ & 0.117 & 0.179 & 0.653 \\
\hline
\end{tabular}

* In type-A models the quantities $p_{1}$ were drawn from the gamma distribution assuming $(\lambda, \theta)=(5,0.5)$, whereas type-B models have $(\lambda, \theta)=(18,0.25)$. 
Table 1 (continued)

Results of the Monte Carlo Experiment;

P2 Models

\begin{tabular}{|c|c|c|c|c|}
\hline \multicolumn{2}{|c|}{ Type-A Models } & \multirow[t]{2}{*}{$\bar{\Theta}(\cdot)$} & \multirow[t]{2}{*}{$\bar{\Omega}(\cdot)$} & \multirow[t]{2}{*}{$\overline{\mathrm{E}}(\cdot)$} \\
\hline \multirow[t]{12}{*}{$\Delta(1, p, 1 ; g)$} & $g=(1,10)$ & & & \\
\hline & $K=50$ & 0.072 & 0.091 & 0.312 \\
\hline & $K=100$ & 0.042 & 0.062 & 0.236 \\
\hline & $K=500$ & 0.026 & 0.044 & 0.198 \\
\hline & $g=(1,1)$ & & & \\
\hline & $\mathrm{K}=50$ & 0.068 & 0.077 & 0.190 \\
\hline & $K=100$ & 0.040 & 0.053 & 0.187 \\
\hline & $K=500$ & 0.022 & 0.034 & 0.197 \\
\hline & $g=(10,1)$ & & & \\
\hline & $K=50$ & 0.067 & 0.068 & 0.321 \\
\hline & $K=100$ & 0.039 & 0.045 & 0.318 \\
\hline & $K=500$ & 0.018 & 0.027 & 0.327 \\
\hline \multicolumn{5}{|l|}{$D(1, p, 1)$} \\
\hline & $K=50$ & 0.125 & 0.206 & 1.390 \\
\hline & $K=100$ & 0.120 & 0.195 & 1.077 \\
\hline & $K=500$ & 0.199 & 0.237 & 0.799 \\
\hline \multicolumn{5}{|c|}{ Type-B Models } \\
\hline \multirow[t]{12}{*}{$\Delta(1, p, 1 ; g)$} & $g=(1,10)$ & & & \\
\hline & $\mathrm{K}=50$ & 0.067 & 0.092 & 0.544 \\
\hline & $K=100$ & 0.041 & 0.065 & 0.397 \\
\hline & $K=500$ & 0.030 & 0.055 & 0.360 \\
\hline & $g=(1,1)$ & & & \\
\hline & $\mathrm{K}=50$ & 0.061 & 0.071 & 0.556 \\
\hline & $K=100$ & 0.033 & 0.039 & 0.588 \\
\hline & $\mathrm{K}=500$ & 0.012 & 0.022 & 0.624 \\
\hline & $g=(10,1)$ & & & \\
\hline & $\mathrm{K}=50$ & 0.074 & 0.097 & 1.031 \\
\hline & $\mathrm{K}=100$ & 0.054 & 0.086 & 1.039 \\
\hline & $\mathrm{K}=500$ & 0.055 & 0.091 & 1.047 \\
\hline \multicolumn{5}{|l|}{$D(1, p, 1)$} \\
\hline & $K=50$ & 0.172 & 0.271 & 1.009 \\
\hline & $K=100$ & 0.193 & 0.309 & 1.118 \\
\hline & $K=500$ & 0.307 & 0.468 & 1.472 \\
\hline
\end{tabular}


Table 1 (continued)

Results of the Monte Carlo Experiment;

P3 Models

\begin{tabular}{|c|c|c|c|c|}
\hline \multicolumn{2}{|c|}{ Type-A Models } & $\bar{\Theta}(\cdot)$ & $\bar{\Omega}(\cdot)$ & $\overline{\mathrm{E}}(\cdot)$ \\
\hline \multirow[t]{12}{*}{$\Delta(1, p, 1 ; g)$} & $g=(1,10)$ & & & \\
\hline & $K=50$ & 0.075 & 0.098 & 0.468 \\
\hline & $K=100$ & 0.049 & 0.086 & 0.397 \\
\hline & $K=500$ & 0.043 & 0.075 & 0.358 \\
\hline & $g=(1,1)$ & & & \\
\hline & $K=50$ & 0.064 & 0.077 & 0.338 \\
\hline & $K=100$ & 0.034 & 0.054 & 0.328 \\
\hline & $K=500$ & 0.021 & 0.042 & 0.342 \\
\hline & $g=(10,1)$ & & & \\
\hline & $\mathrm{K}=50$ & 0.090 & 0.220 & 0.591 \\
\hline & $K=100$ & 0.083 & 0.138 & 0.588 \\
\hline & $K=500$ & 0.112 & 0.159 & 0.597 \\
\hline \multicolumn{5}{|l|}{$D(1, p, 1)$} \\
\hline & $K=50$ & 0.173 & 0.275 & 1.813 \\
\hline & $K=100$ & 0.178 & 0.277 & 1.429 \\
\hline & $K=500$ & 0.218 & 0.312 & 1.135 \\
\hline \multicolumn{5}{|c|}{ Type-B Models } \\
\hline \multirow[t]{12}{*}{$\Delta(1, p, 1 ; g)$} & $g=(1,10)$ & & & \\
\hline & $\mathrm{K}=50$ & 0.065 & 0.088 & 0.590 \\
\hline & $K=100$ & 0.036 & 0.055 & 0.518 \\
\hline & $\mathrm{K}=500$ & 0.025 & 0.049 & 0.522 \\
\hline & $g=(1,1)$ & & & \\
\hline & $\mathrm{K}=50$ & 0.085 & 0.129 & 1.065 \\
\hline & $K=100$ & 0.055 & 0.109 & 1.122 \\
\hline & $K=500$ & 0.058 & 0.110 & 1.179 \\
\hline & $g=(10,1)$ & & & \\
\hline & $K=50$ & 0.120 & 0.227 & 1.595 \\
\hline & $K=100$ & 0.105 & 0.215 & 1.599 \\
\hline & $K=500$ & 0.121 & 0.216 & 1.620 \\
\hline \multicolumn{5}{|l|}{$D(1, p, 1)$} \\
\hline & $K=50$ & 0.341 & 0.579 & 1.749 \\
\hline & $K=100$ & 0.420 & 0.680 & 1.980 \\
\hline & $K=500$ & 0.605 & 0.902 & 2.279 \\
\hline
\end{tabular}


Table 2

Results of the Monte Carlo Experiment;

L1 and L2 Models

\begin{tabular}{|c|c|c|c|c|}
\hline L1 Models & & $\bar{\Theta}(\cdot)$ & $\bar{\Omega}(\cdot)$ & $\overline{\mathrm{E}}(\cdot)$ \\
\hline \multirow[t]{12}{*}{$\Delta(1, p, 1 ; g)$} & $g=(1,10)$ & & & \\
\hline & $\mathrm{K}=50$ & 0.071 & 0.208 & 1.409 \\
\hline & $K=100$ & 0.037 & 0.155 & 1.422 \\
\hline & $K=500$ & 0.029 & 0.132 & 1.449 \\
\hline & $g=(1,1)$ & & & \\
\hline & $K=50$ & 0.071 & 0.236 & 1.710 \\
\hline & $K=100$ & 0.052 & 0.197 & 1.735 \\
\hline & $K=500$ & 0.042 & 0.168 & 1.779 \\
\hline & $g=(10,1)$ & & & \\
\hline & $K=50$ & 0.073 & 0.241 & 1.959 \\
\hline & $K=100$ & 0.049 & 0.215 & 1.979 \\
\hline & $K=500$ & 0.047 & 0.189 & 1.991 \\
\hline \multicolumn{5}{|l|}{$D(1, p, 1)$} \\
\hline & $K=50$ & 0.199 & 0.532 & 2.059 \\
\hline & $K=100$ & 0.266 & 0.672 & 2.238 \\
\hline & $\mathrm{K}=500$ & 0.415 & 0.968 & 2.468 \\
\hline \multicolumn{5}{|l|}{ L2 Models } \\
\hline \multirow[t]{11}{*}{$\Delta(1, p, 1 ; g)$} & $g=(1,10)$ & & & \\
\hline & $\mathrm{K}=50$ & 0.082 & 0.642 & 1.746 \\
\hline & $K=100$ & 0.055 & 0.675 & 1.769 \\
\hline & $\begin{array}{l}K=500 \\
g=(1,1)\end{array}$ & 0.056 & 0.718 & 1.828 \\
\hline & $K=50$ & 0.101 & 0.724 & 2.328 \\
\hline & $K=100$ & 0.081 & 0.750 & 2.359 \\
\hline & $K=500$ & 0.084 & 0.818 & 2.428 \\
\hline & $g=(10,1)$ & & & \\
\hline & $\mathrm{K}=50$ & 0.099 & 0.774 & 2.719 \\
\hline & $K=100$ & 0.095 & 0.830 & 2.719 \\
\hline & $\mathrm{K}=500$ & 0.096 & 0.852 & 2.717 \\
\hline \multicolumn{5}{|l|}{$D(1, p, 1)$} \\
\hline & $K=50$ & 0.295 & 0.789 & 2.818 \\
\hline & $K=100$ & 0.379 & 0.968 & 3.028 \\
\hline & $K=500$ & 0.575 & 1.295 & 3.299 \\
\hline
\end{tabular}


Table 2 (continued)

Results of the Monte Carlo Experiment;

L3 Models

\begin{tabular}{ccccc}
\hline & & $\bar{\Theta}(\cdot)$ & $\bar{\Omega}(\cdot)$ & $\overline{\mathrm{E}}(\cdot)$ \\
\hline$\Delta(1, p, 1 ; g)$ & $g=(1,10)$ & & & \\
$\mathrm{K}=50$ & 0.099 & 0.410 & 3.132 \\
$\mathrm{~K}=100$ & 0.091 & 0.396 & 2.938 \\
$\mathrm{~K}=500$ & 0.093 & 0.378 & 3.048 \\
$g=(1,1)$ & & & \\
$\mathrm{K}=50$ & 0.135 & 0.579 & 3.895 \\
$\mathrm{~K}=100$ & 0.131 & 0.561 & 3.938 \\
$\mathrm{~K}=500$ & 0.139 & 0.539 & 4.039 \\
& $g=(10,1)$ & & & \\
& $\mathrm{K}=50$ & 0.165 & 0.649 & 4.347 \\
$\mathrm{~K}=100$ & 0.155 & 0.619 & 4.379 \\
$\mathrm{~K}=500$ & 0.159 & 0.608 & 4.370 \\
\hline $\mathrm{K}(1, p, 1)$ & & & \\
& $\mathrm{K}=50$ & 0.439 & 1.169 & 4.581 \\
& $\mathrm{~K}=100$ & 0.519 & 1.322 & 4.792 \\
$\mathrm{~K}=500$ & 0.742 & 1.651 & 5.022 \\
\hline \hline
\end{tabular}


Figure 2

Frontiers of the Price Output Set;

Model P1A; K=50
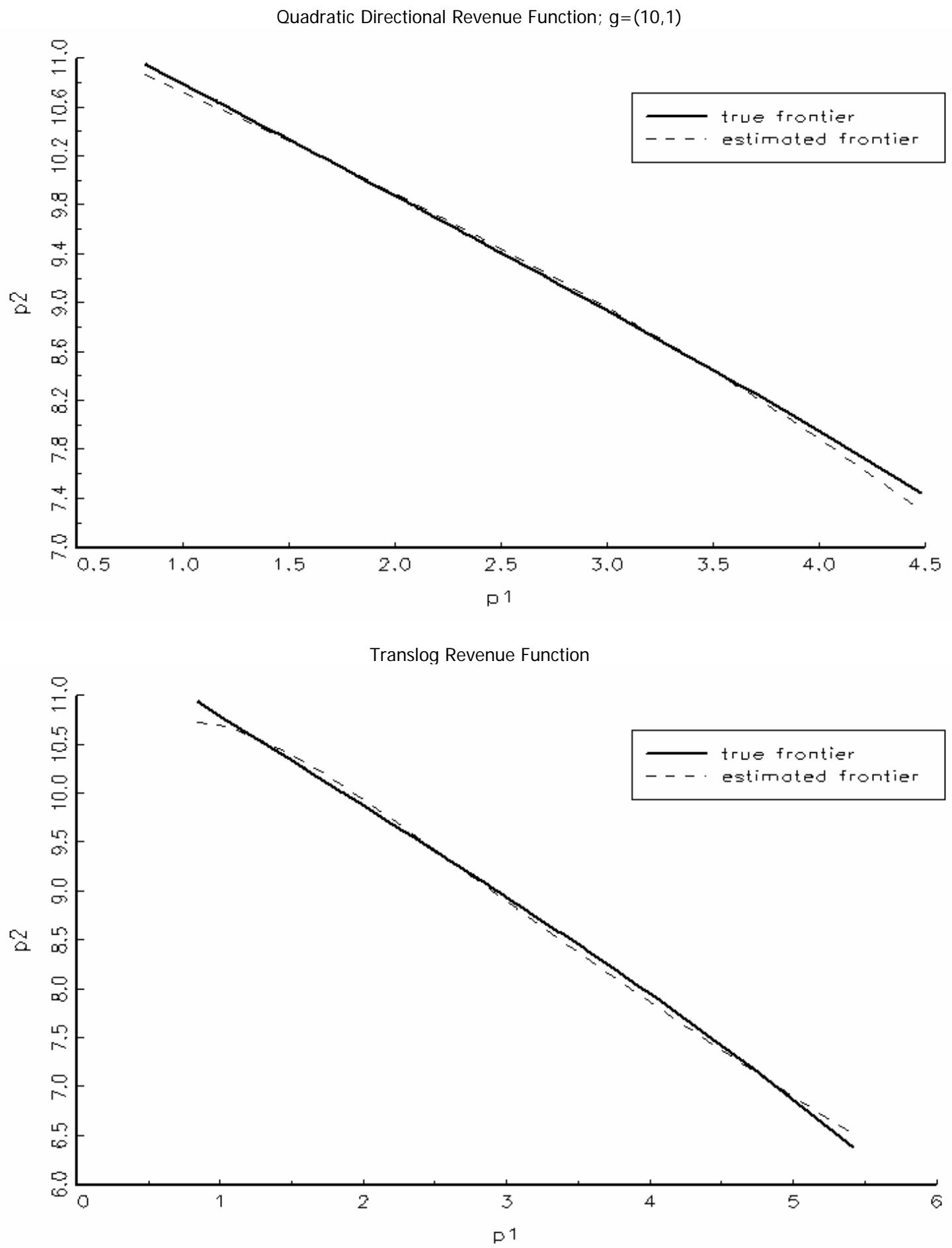

Figure 2 (continued) 
Model P2B; K=100

Quadratic Directional Revenue Function; $g=(1,1)$

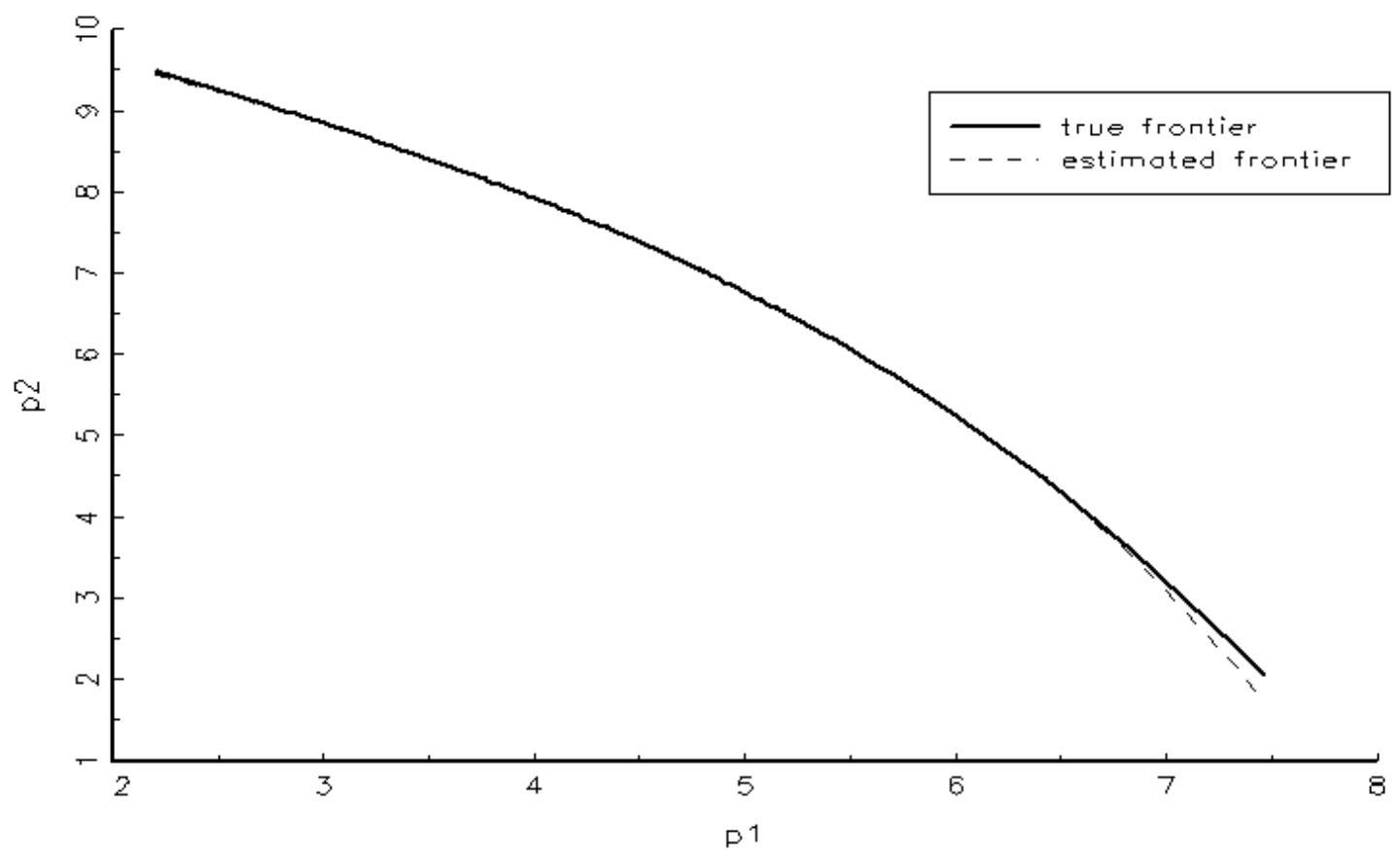

Translog Revenue Function

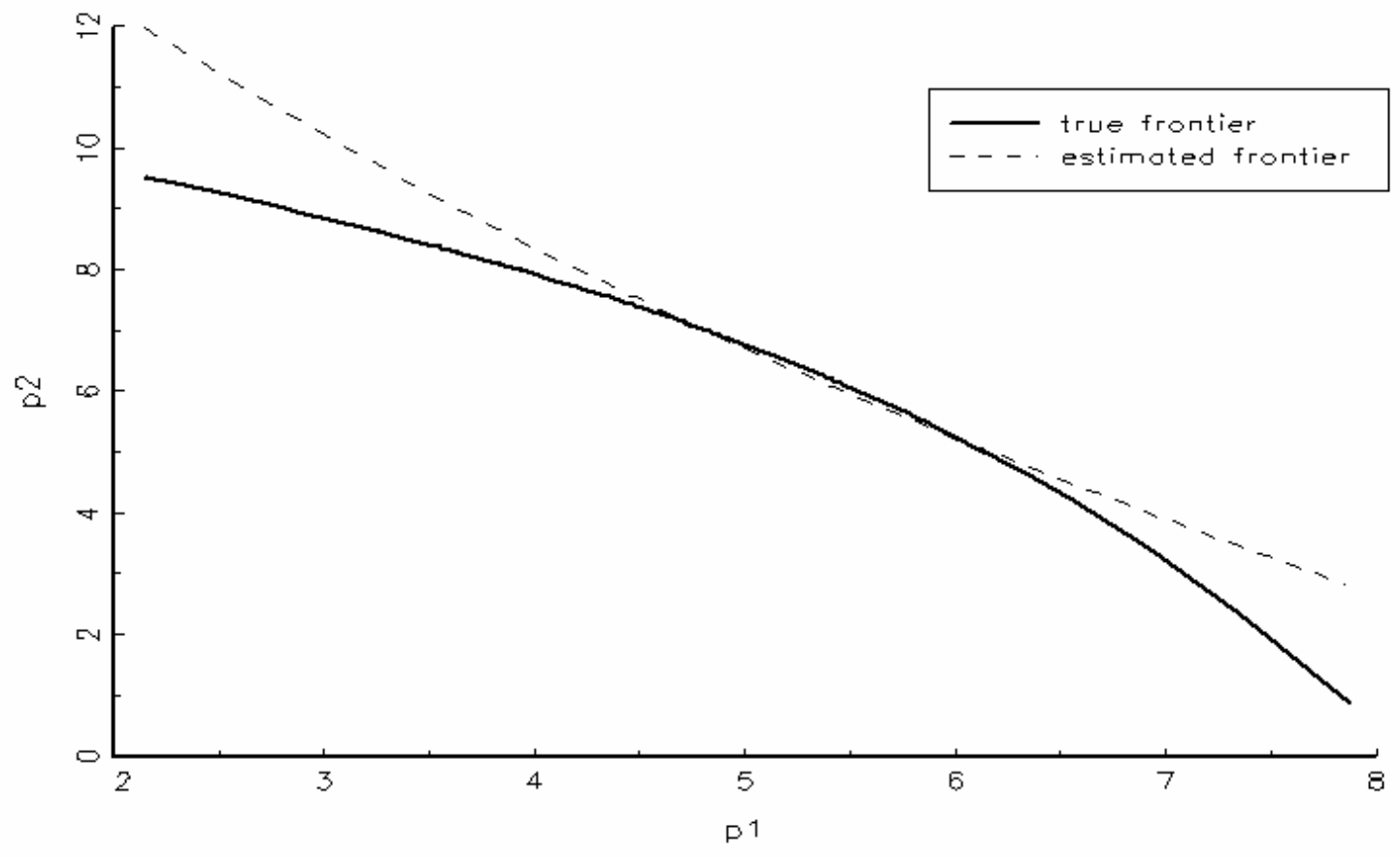

Figure 2 (continued) 
Model P3A; K=500
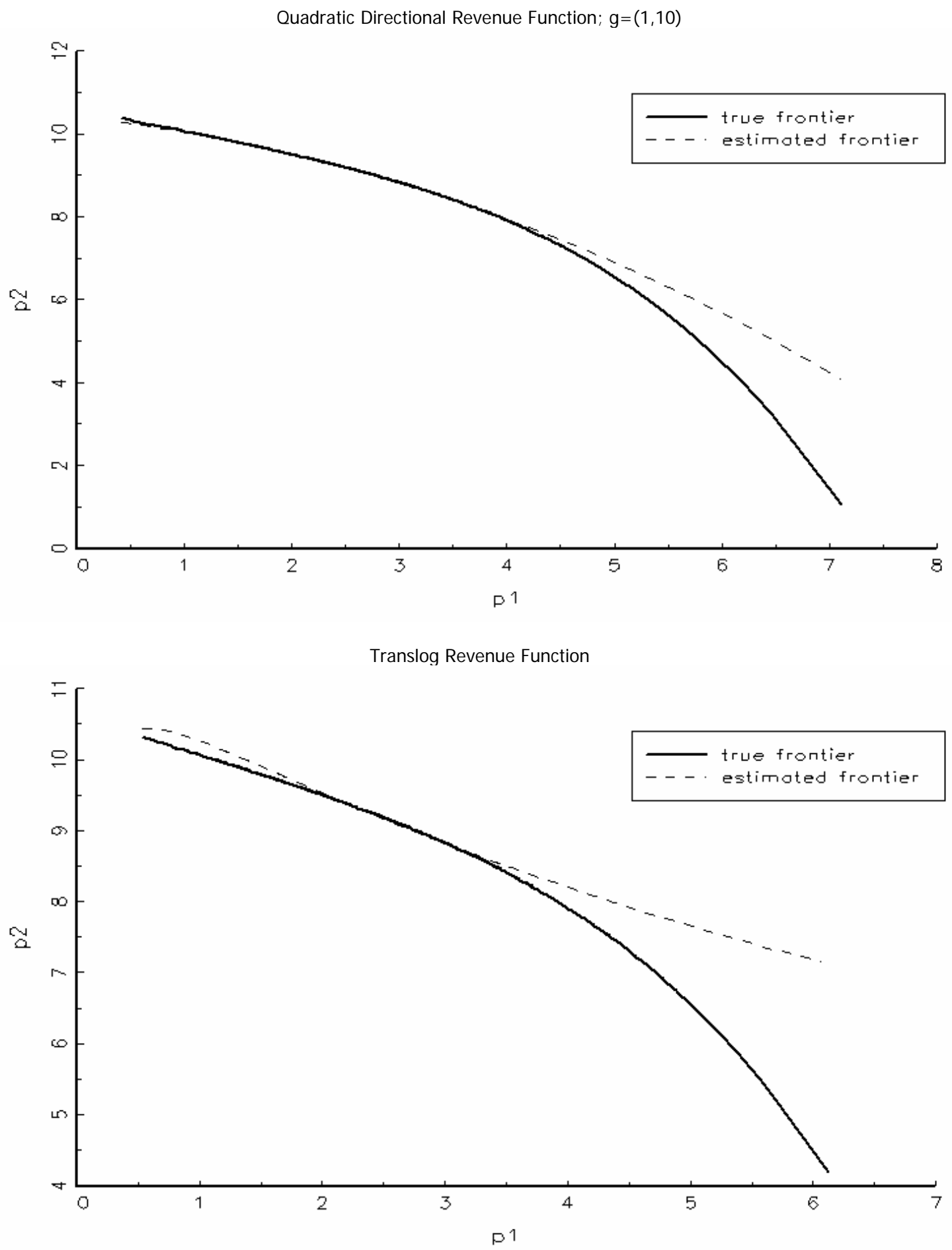

Figure 3

Frontiers of the Price Output Set; 


\section{Model L1; K=50}

Quadratic Directional Revenue Function; $g=(10,1)$

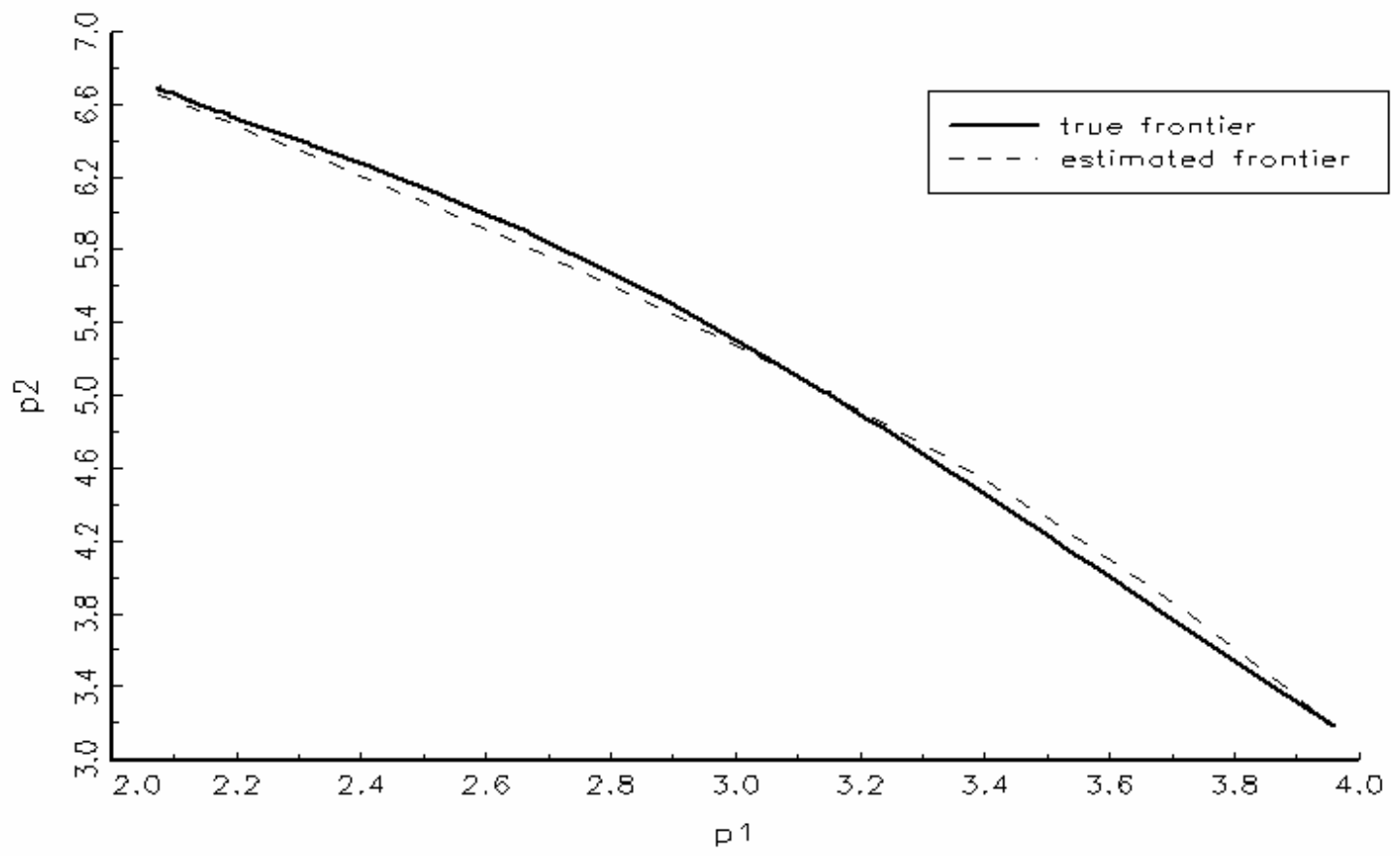

Translog Revenue Function

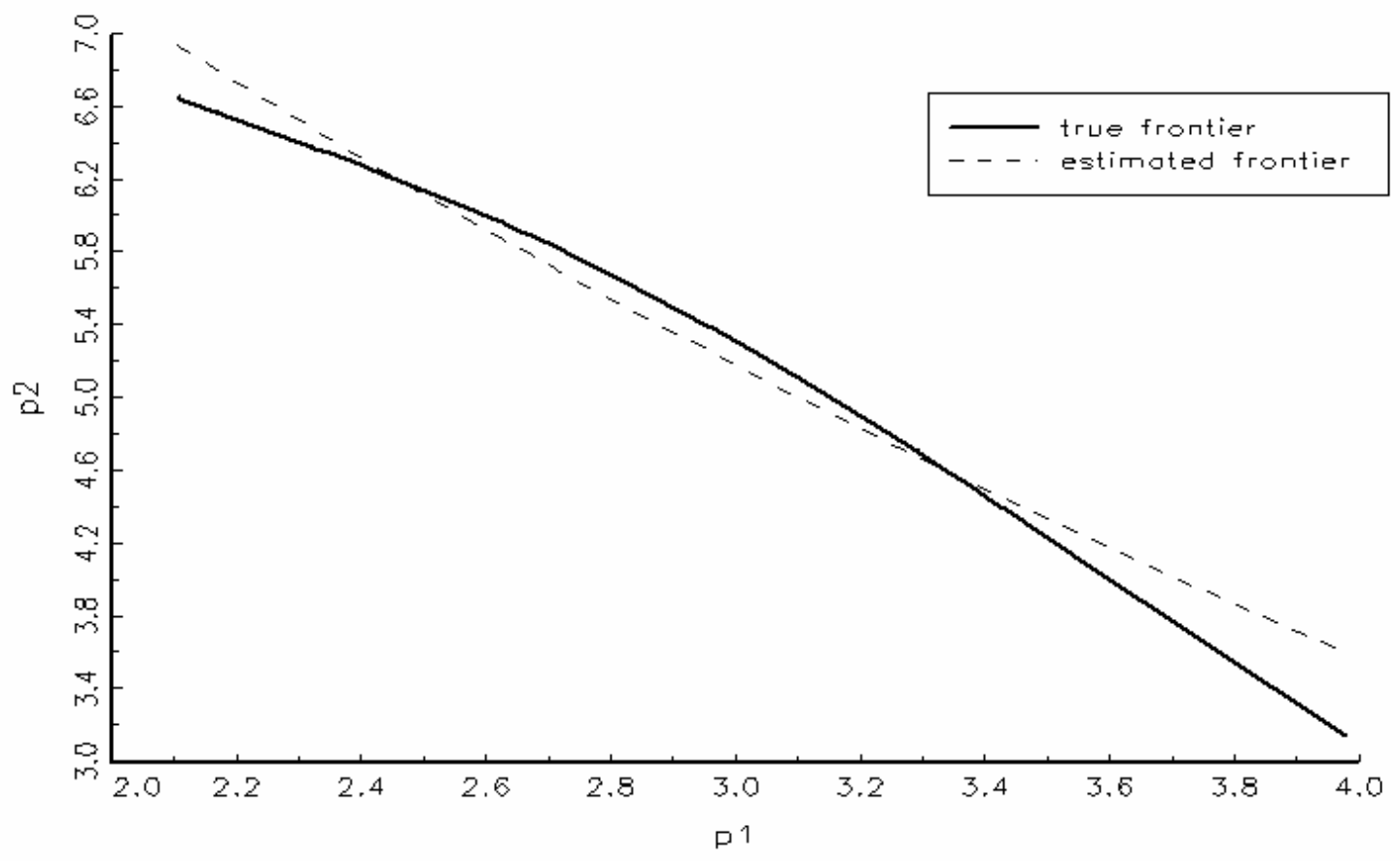


Figure 3 (continued)

Model L2; K=100
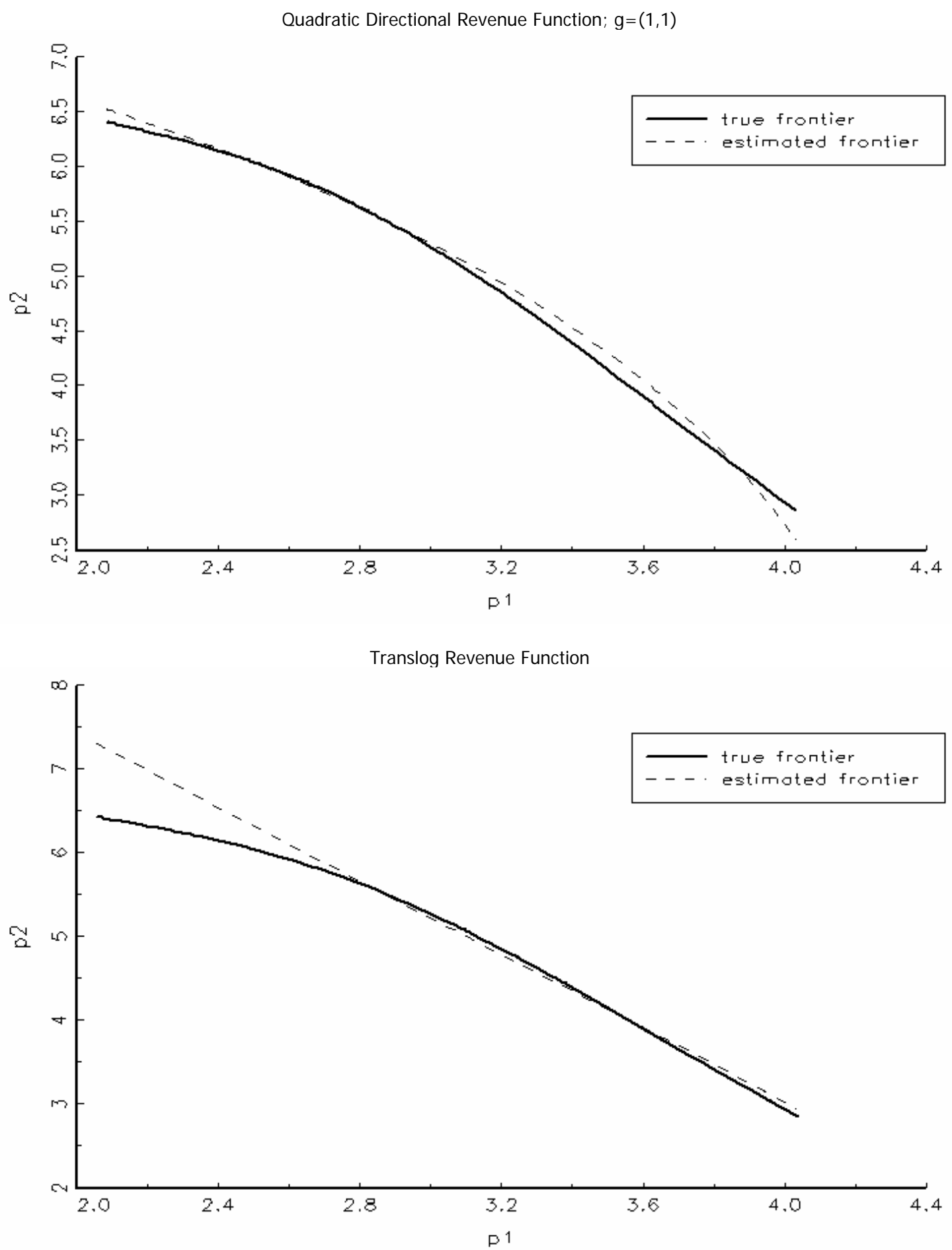
Figure 3 (continued)

Model L3; K=500
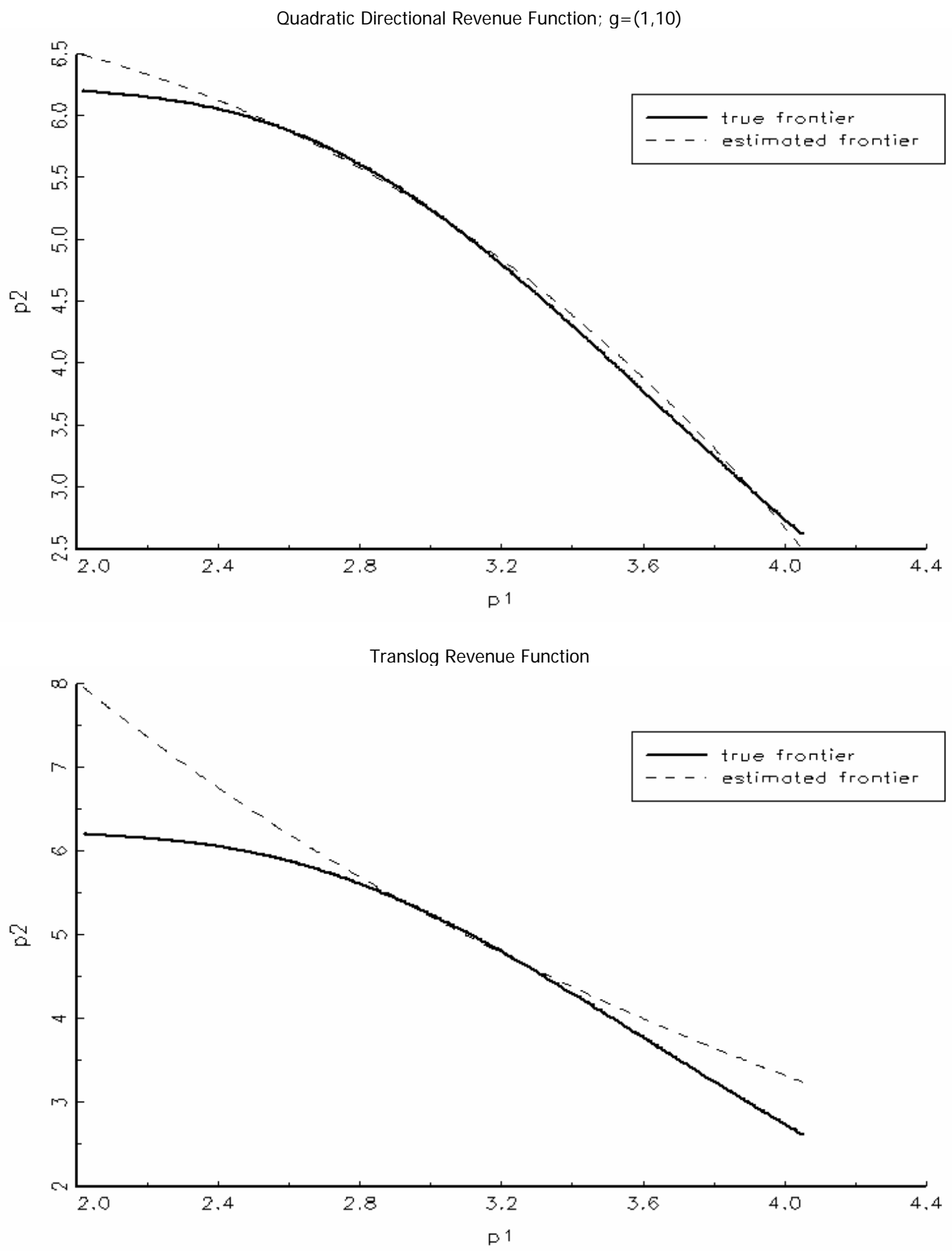


\section{Conclusions}

Our results with the revenue function representations in price space with Shephard and directional output distance functions are similar to the conclusions reached by Färe, Martins-Filho, and Vardanyan (2008) for quantity space estimates of distance functions using translog and quadratic functional forms. While the reliability of the quadratic parameterizations has been established once again, the relative failure of the translog specifications to precisely approximate the true frontier is as pronounced in the price space as was shown to be in the quantity space.

In terms of our effort here with respect to the revenue function, we have provided evidence that translog specifications will yield imprecise estimates of technology, despite the fact that they satisfy the homogeneity property. Fortunately, the dual price space directional distance function provides a specification that is consistent with the quadratic specification that provided more precise approximations of the technology, thus providing an alternative way to identify the revenue function. 


\section{Appendix}

We provide a brief sketch of the proof of the lemma. It is similar to Luenberger's (1995, p. 100) proof of the relation between the utility function and the benefit function.

Recall that the revenue function is convex in prices and thus continuous on the interior of $\Re_{+}^{M}$ (Shephard, 1970, p. 230). It is also nondecreasing in prices.

Following Luenberger (1995, p. 100), given that

i) $R(x, p+\alpha g)<R(x, p), \alpha>0$, if $R(x, p)=R$ then $\triangle(x, p, R ; g)=0$.

Conversely, if $p \in$ Interior of $\Re_{+}^{M}$ and $\triangle(x, p, R ; g)=0$, then $R(x, p)=R$.

Details:

Assume that $R(x, p)=R$, then $\triangle() \geqq$.0 . Since i) holds, $R(x, p+\alpha g)<R(x, p), \alpha>0$, thus $\triangle(x, p, R ; g)=$ 0 .

Conversely let $p \in$ Interior of $\Re_{+}^{M}$ then $\triangle(x, p, R ; g)=0$, implies $R(x, p) \leqq R$ and $R(x, p+\alpha g)<$ $R(x, p)$. By continuity of $R$ in $p, R(x, p)=R$.

\section{References}

[1] Chambers, R. G. (1988). Applied Production Analysis: A Dual Approach, Cambridge University Press, Cambridge.

[2] Chambers, R. G. (1998). 'Input and Output Indicators,' in Index Numbers: Essays in Honour of Sten Malmquist, R. Färe, S. Grosskopf and R.R. Russell (eds), Kluwer: Boston.

[3] Chambers, R. G., Y. Chung and R. Färe (1996). "Benefit and Distance Functions" Journal of Economic Theory 70(2) (August): 407-19

[4] Christensen, L.R., D.W. Jorgenson and L.J. Lau (1975). 'Transcendental Logarithmic Utility Functions,' American Economic Review 65(3), 367-383.

[5] Diewert, W.E. (1971). 'An Application of Shephard's Duality Theorem: A Generalized Leontief Production Function,' Journal of Political Economy 79, 481-507. 
[6] Diewert, W.E. (2002).'The Quadratic Approximation Lemma and Decompositions of the Superlative Indexes,' Journal of Economics and Social Measurement, 28, 63-88.

[7] Diewert, W.E. and T.J. Wales (1987). 'Flexible Functional Forms and Global Curvature Conditions,' Econometrica 55(1), 43-68.

[8] Färe, R. and S. Grosskopf (2004). New Directions: Efficiency and Productivity. Kluwer Academic Publishers: Boston.

[9] Färe, R. and S. Grosskopf. (2000). "Theory and Application of Directional Distance Functions" Journal of Productivity Analysis 13(2) (March): 93-103.

[10] Färe, R., S. Grosskopf, K. Hayes, D. Margaritis (in press). 'Estimating Demand with Distance Functions: Parameterization of the Primal and Dual,' Journal of Econometrics.

[11] Färe, R. and A. Lundberg (2006). 'Parameterizing the Shortage Function,' mimeo.

[12] Färe, R., C. Martins-Filho and M. Vardanyan (2008). "On Functional Form Representation of Multi-Output Production Technologies," mimeo.

[13] Färe, R. and D. Primont (1995). Multi-Output Production and Duality: Theory and Applications. Kluwer Academic Publishers: Boston.

[14] Färe, R. and K. Sung (1986). 'On Second-Order Taylor's Series Approximations and Linear Homogeneity,' Aequationes Mathematicae 30, 180-186.

[15] Feng, G. and A. Serletis (2008). 'Productivity Trends in U.S. Manufacturing: Evidence from the NQ and AIM cost functions,' Journal of Econometrics 142(1), 281-311.

[16] Luenberger, D. G. (1992). "Benefit Functions and Duality," Journal of Mathematical Economics 21: 461-481.

[17] Luenberger, D. G. (1995). Microeconomic Theory, McGraw-Hill: New York.

[18] Shephard, R. W. (1970). Theory of Cost and Production Functions, Princeton: Princeton University Press. 


\section{CESifo Working Paper Series}

for full list see www.cesifo-group.org/wp

(address: Poschingerstr. 5, 81679 Munich, Germany, office@cesifo.de)

2341 Helmut Seitz, Minimum Standards, Fixed Costs and Taxing Autonomy of Subnational Governments, June 2008

2342 Robert S. Chirinko, Leo de Haan and Elmer Sterken, Asset Price Shocks, Real Expenditures, and Financial Structure: A Multi-Country Analysis, July 2008

2343 Wolfgang Leininger, Evolutionarily Stable Preferences in Contests, July 2008

2344 Hartmut Egger and Udo Kreickemeier, Fairness, Trade, and Inequality, July 2008

2345 Ngo Van Long and Bodhisattva Sengupta, Yardstick Competition, Corruption, and Electoral Incentives, July 2008

2346 Florian Baumann, Employment Protection: The Case of Limited Enforceability, July 2008

2347 Alessandro Balestrino, Cinzia Ciardi and Claudio Mammini, On the Causes and Consequences of Divorce, July 2008

2348 Dirk Schindler and Benjamin Weigert, Insuring Educational Risk: Opportunities versus Income, July 2008

2349 Lammertjan Dam and Ben J. Heijdra, The Environmental and Macroeconomic Effects of Socially Responsible Investment, July 2008

2350 Avner Greif, Contract Enforcement and Institutions among the Maghribi Traders: Refuting Edwards and Ogilvie, July 2008

2351 Helmuth Cremer, Philippe De Donder, Dario Maldonado and Pierre Pestieau, Habit Formation and Labor Supply, July 2008

2352 Francesco Menoncin and Paolo M. Panteghini, The Johansson-Samuelson Theorem in General Equilibrium: A Rebuttal, July 2008

2353 Michael Kaganovich and Itzhak Zilcha, Alternative Social Security Systems and Growth, July 2008

2354 Keith Blackburn, Kyriakos C. Neanidis and M. Emranul Haque, Corruption, Seigniorage and Growth: Theory and Evidence, July 2008

2355 Edward Castronova, A Test of the Law of Demand in a Virtual World: Exploring the Petri Dish Approach to Social Science, July 2008 
2356 Harald Badinger and Peter Egger, GM Estimation of Higher-Order Spatial Autoregressive Processes in Cross-Section Models with Heteroskedastic Disturbances, July 2008

2357 Wolfgang Buchholz and Jan Schumacher, Discounting the Long-Distant Future: A Simple Explanation for the Weitzman-Gollier-Puzzle, July 2008

2358 Luca Anderlini, Leonardo Felli and Alessandro Riboni, Statute Law or Case Law?, July 2008

2359 Guglielmo Maria Caporale, Davide Ciferri and Alessandro Girardi, Are the Baltic Countries Ready to Adopt the Euro? A Generalised Purchasing Power Parity Approach, July 2008

2360 Erkki Koskela and Ronnie Schöb, Outsourcing of Unionized Firms and the Impacts of Labour Market Policy Reforms, July 2008

2361 Francisco Alvarez-Cuadrado and Ngo Van Long, A Permanent Income Version of the Relative Income Hypothesis, July 2008

2362 Gabrielle Demange, Robert Fenge and Silke Uebelmesser, Financing Higher Education and Labor Mobility, July 2008

2363 Alessandra Casarico and Alessandro Sommacal, Labor Income Taxation, Human Capital and Growth: The Role of Child Care, August 2008

2364 Antonis Adam, Manthos D. Delis and Pantelis Kammas, Fiscal Decentralization and Public Sector Efficiency: Evidence from OECD Countries, August 2008

2365 Stefan Voigt, The (Economic) Effects of Lay Participation in Courts - A Cross-Country Analysis, August 2008

2366 Tobias König and Andreas Wagener, (Post-)Materialist Attitudes and the Mix of Capital and Labour Taxation, August 2008

2367 Ximing Wu, Andreas Savvides and Thanasis Stengos, The Global Joint Distribution of Income and Health, August 2008

2368 Alejandro Donado and Klaus Wälde, Trade Unions Go Global!, August 2008

2369 Hans Gersbach and Hans Haller, Exit and Power in General Equilibrium, August 2008

2370 Jan P.A.M. Jacobs and Jan-Egbert Sturm, The Information Content of KOF Indicators on Swiss Current Account Data Revisions, August 2008

2371 Oliver Hülsewig, Johannes Mayr and Timo Wollmershäuser, Forecasting Euro Area Real GDP: Optimal Pooling of Information, August 2008

2372 Tigran Poghosyan and Jakob de Haan, Determinants of Cross-Border Bank Acquisitions in Transition Economies: A Latent Class Analysis, August 2008 
2373 David Anthoff and Richard S.J. Tol, On International Equity Weights and National Decision Making on Climate Change, August 2008

2374 Florian Englmaier and Arno Schmöller, Reserve Price Formation in Online Auctions, August 2008

2375 Karl Farmer, Birgit Friedl and Andreas Rainer, Effects of Unilateral Climate Policy on Terms of Trade, Capital Accumulation, and Welfare in a World Economy, August 2008

2376 Monika Bütler, Stefan Staubli and Maria Grazia Zito, The Role of the Annuity’s Value on the Decision (Not) to Annuitize: Evidence from a Large Policy Change, August 2008

2377 Inmaculada Martínez-Zarzoso, The Impact of Urbanization on $\mathrm{CO}_{2}$ Emissions: Evidence from Developing Countries, August 2008

2378 Brian Roberson and Dmitriy Kvasov, The Non-Constant-Sum Colonel Blotto Game, August 2008

2379 Ian Dew-Becker, How Much Sunlight Does it Take to Disinfect a Boardroom? A Short History of Executive Compensation Regulation, August 2008

2380 Cécile Aubert, Oliver Falck and Stephan Heblich, Subsidizing National Champions: An Evolutionary Perspective, August 2008

2381 Sebastian Buhai, Miguel Portela, Coen Teulings and Aico van Vuuren, Returns to Tenure or Seniority?, August 2008

2382 Erkki Koskela and Jan König, Flexible Outsourcing, Profit Sharing and Equilibrium Unemployment, August 2008

2383 Torberg Falch and Justina AV Fischer, Does a Generous Welfare State Crowd out Student Achievement? Panel Data Evidence from International Student Tests, September 2008

2384 Pedro Gomes and François Pouget, Corporate Tax Competition and the Decline of Public Investment, September 2008

2385 Marko Koethenbuerger, How Do Local Governments Decide on Public Policy in Fiscal Federalism? Tax vs. Expenditure Optimization, September 2008

2386 Ronald McKinnon and Gunther Schnabl, China’s Exchange Rate Impasse and the Weak U.S. Dollar, September 2008

2387 Yan-Leung Cheung, Yin-Wong Cheung and Alan T.K. Wan, A High-Low Model of Daily Stock Price Ranges, September 2008

2388 Louis Eeckhoudt and Harris Schlesinger, Changes in Risk and the Demand for Saving, September 2008 
2389 Carsten Hefeker and Blandine Zimmer, Uncertainty and Fiscal Policy in an Asymmetric Monetary Union, September 2008

2390 Jay Pil Choi and Byung-Cheol Kim, Net Neutrality and Investment Incentives, September 2008

2391 Marcel Gérard, Financing Bologna, the Internationally Mobile Students in European Higher Education, September 2008

2392 Annette Alstadsæter and Knut Reidar Wangen, Corporations' Choice of Tax Regime when Transition Costs are Small and Income Shifting Potential is Large, September 2008

2393 António Afonso and Christophe Rault, 3-Step Analysis of Public Finances Sustainability: the Case of the European Union, September 2008

2394 Betsey Stevenson and Justin Wolfers, Economic Growth and Subjective Well-Being: Reassessing the Easterlin Paradox, September 2008

2395 Bernhard Eckwert and Itzhak Zilcha, Private Investment in Higher Education: Comparing Alternative Funding Schemes, September 2008

2396 Øystein Foros, Hans Jarle Kind and Jan Yngve Sand, Slotting Allowances and Manufacturers’ Retail Sales Effort, September 2008

2397 Mohammad Reza Farzanegan, Illegal Trade in the Iranian Economy: Evidence from a Structural Model, September 2008

2398 Olivier Bos, Charity Auctions for the Happy Few, September 2008

2399 Robert S. Chirinko and Debdulal Mallick, The Marginal Product of Capital: A Persistent International Puzzle, September 2008

2400 Ben D’Exelle and Arno Riedl, Elite Capture, Political Voice and Exclusion from Aid: An Experimental Study, September 2008

2401 Torben M. Andersen and Joydeep Bhattacharya, On Myopia as Rationale for Social Security, September 2008

2402 Fabienne Llense, French CEO Compensations: What is the Cost of a Mandatory Upper Limit?, September 2008

2403 Valentina Bosetti, Carlo Carraro, Alessandra Sgobbi and Massimo Tavoni, Delayed Action and Uncertain Targets. How Much Will Climate Policy Cost?, September 2008

2404 Robert G. Chambers, Rolf Färe, Shawna Grosskopf and Michael Vardanyan, Generalized Quadratic Revenue Functions, September 2008 